\title{
Clusterin Expression in Malignant Lymphomas: A Survey of 266 Cases
}

Helene Saffer, M.D., Amer Wahed, M.D., Georgios Z. Rassidakis, M.D., L. Jeffrey Medeiros, M.D. Department of Pathology (HS, AW), The University of Texas-Houston Health Sciences Center; and Department of Hematopathology (GZR, LJM), The University of Texas-M.D. Anderson Cancer Center, Houston, Texas

Clusterin expression has been reported to be characteristic of systemic anaplastic large cell lymphoma and usually negative in cutaneous anaplastic large cell lymphoma as well as other lymphoma types. We surveyed clusterin expression using immunohistochemical methods in 266 cases of nonHodgkin's lymphoma and Hodgkin's disease to further assess the diagnostic utility of this marker. Clusterin immunostaining was observed in 40 of 49 (82\%) systemic anaplastic large cell lymphomas and 12 of 29 (41\%) cutaneous anaplastic large cell lymphomas. Clusterin also was expressed in 5 of 43 (12\%) diffuse large B-cell lymphomas (4 of 5 CD30+), 1 of $14(7 \%)$ peripheral T-cell lymphomas, 1 of 32 (3\%) cases of nodular sclerosis Hodgkin's disease, and 1 case of mycosis fungoides in large cell transformation. Clusterin was negative in all other neoplasms assessed including follicular lymphoma of all grades $(n=24)$, mantle cell lymphoma $(n=$ 13), marginal zone B-cell lymphoma $(n=12)$, precursor T-cell or B-cell lymphoblastic leukemia/lymphoma $(n=10)$, mixed cellularity Hodgkin's disease $(n=8)$, chronic lymphocytic leukemia/small lymphocytic lymphoma $(n=7)$, Burkitt lymphoma $(n=$ $7)$, mycosis fungoides $(n=4)$, nodular lymphocyte predominant Hodgkin's disease $(n=3)$, lymphoplasmacytic lymphoma/Waldenstrom macroglobulinemia $(n=2)$, and plasmacytoma $(n=2)$. We conclude that clusterin is a marker of anaplastic large cell lymphoma and that addition of clusterin to antibody panels designed to distinguish systemic anaplastic large cell lymphoma from classical Hodgkin's disease is useful. However, clusterin is

Copyright $\odot 2002$ by The United States and Canadian Academy of Pathology, Inc.

VOL. 15, NO. 11, P. 1221, 2002 Printed in the U.S.A.

Date of acceptance: August 21, 2002.

Dr. Saffer is currently a member of the Department of Pathology, The

University of California at San Diego, San Diego, California.

Address reprint requests to: L. Jefffrey Medeiros, M.D., Department of Hematopathology, Box 72, M.D. Anderson Cancer Center, 1515 Holcombe Boulevard, Houston, TX 77030; e-mail: jmedeiro@mdanderson.org; fax: 713-745-0736.

DOI: 10.1097/01.MP.0000036386.87517.AA also positive in a substantial subset of cutaneous anaplastic large cell lymphomas, a smaller subset of diffuse large B-cell lymphomas, and rarely in cases of peripheral T-cell lymphoma and nodular sclerosis Hodgkin's disease.

KEY WORDS: Anaplastic large cell lymphoma, Clusterin, Hodgkin's disease, Immunohistochemistry, Non-Hodgkin's lymphoma.

Mod Pathol 2002;15(11):1221-1226

Clusterin is a glycoprotein that was first isolated from ram rete testis fluid and Sertoli cell-culture medium and its name is derived from the ability of this protein to induce clustering of Sertoli cells $(1,2)$. Clusterin has numerous other names, including glycoprotein III, apolipoprotein J (ApoJ), testosterone-repressed prostate message-2 (TRPM-2) and sulfated glycoprotein-2 (SGP-2). Clusterin has a molecular weight of $80 \mathrm{kd}$ and is composed of two 40-kd alpha and beta subunits, joined by a unique five disulfide bond motif ( 3 , $4)$. The gene that encodes for clusterin is located on chromosome 8p21 (4-6).

Clusterin is highly conserved across species and has a wide tissue distribution suggesting that it has an important biological role. Numerous functions for clusterin have been proposed, including complement regulation, cell aggregation, lipid transport, and response to cell stress or injury $(1,4,7)$. Clusterin also is involved in apoptosis, reported to either protect cells from apoptosis or promote cell death in different experimental systems (8-10). Clusterin is found in many different body fluids (4) and is also present in most organs, primarily within epithelial cells, with the highest levels in testis, epididymis, liver, and stomach (4). Clusterin is also expressed in different types of carcinoma including those arising in the breast, kidney, bladder, prostate, and ovary (11-15).

Clusterin expression has been assessed infrequently in malignant lymphomas. Wellmann and colleagues (16) have reported that clusterin is positive in systemic anaplastic large cell lymphoma, 
negative in cutaneous anaplastic large cell lymphoma, and rarely expressed in other types of lymphoma. These results suggest that clusterin may be a valuable addition to antibody panels designed to distinguish systemic anaplastic large cell lymphoma from its morphologic mimics.

In this study, we surveyed clusterin expression in a large number of cases of non-Hodgkin's lymphoma and Hodgkin's disease. We show that clusterin positivity, in a cytoplasmic and paranuclear distribution, is found in most cases of systemic anaplastic large cell lymphoma, as was reported previously (16). However, we also observed clusterin expression in approximately $40 \%$ of cutaneous anaplastic large cell lymphoma, $10 \%$ of diffuse large B-cell lymphomas, and in rare cases of peripheral T-cell lymphoma and nodular sclerosis Hodgkin's disease.

\section{MATERIALS AND METHODS}

We analyzed 266 cases of previously diagnosed non-Hodgkin's lymphoma and Hodgkin's disease from numerous body sites, including 49 cases of systemic anaplastic large cell lymphoma and 29 cases of cutaneous anaplastic large cell lymphoma. We also included seven cases of lymphomatoid papulosis as these lesions are closely related to cutaneous anaplastic large cell lymphoma (17). The cases assessed were a mixture of biopsy specimens obtained at other hospitals and referred to our institution for review and biopsy specimens obtained at our hospital. As a result, these specimens were fixed and processed in a non-uniform manner. The diagnosis for each case was based on histologic criteria with appropriate immunohistochemical or flow cytometry immunophenotypic studies as needed. Molecular studies to assess for T-cell or B-cell clonality or for specific chromosomal translocations were performed on a small subset of cases.

Clusterin expression was assessed immunohistochemically using fixed, paraffin-embedded tissue sections and a mouse monoclonal IgGl anti-human clusterin antibody (Upstate Biotechnology, Lake Placid, NY) that recognizes the $\alpha$ subunit of the clusterin heterodimer. Briefly, $5 \mu \mathrm{m}$ sections were mounted on glass slides, deparaffinized, rehydrated, and then heat-induced antigen retrieval was performed as described previously $(18,19)$. Endogenous peroxidase was blocked with $\mathrm{H}_{2} \mathrm{O}_{2}$. The slides were incubated with the clusterin antibody overnight at room temperature. Either 3-amino-9-ethyl carbazol or diaminobenzidine was used as the chromogen. Positive and negative (no primary antibody) controls were included with each run of samples.

\section{RESULTS}

Clusterin was positive in 93 of 266 (35\%) lymphoid neoplasms assessed (Table 1). For clusterin to be considered positive in this study we required cytoplasmic positivity, usually present in a paranuclear or golgi distribution.

TABLE 1. Clusterin Expression in 266 Cases of Non-Hodgkin's Lymphoma and Hodgkin's Disease

\begin{tabular}{|c|c|}
\hline Non-Hodgkin’s Lymphoma & $\begin{array}{l}\text { Clusterin Positive/ } \\
\text { Total Number (\%) }\end{array}$ \\
\hline Anaplastic large cell lymphoma & $40 / 49(82)$ \\
\hline ALK-1 positive & $16 / 17(94)$ \\
\hline ALK-1 negative & $20 / 28(71)$ \\
\hline Cutaneous anaplastic large cell lymphoma & $12 / 29(41)$ \\
\hline ALK-1 positive & $1 / 1(100)$ \\
\hline ALK-1 negative & $11 / 28(37)$ \\
\hline Lymphomatoid papulosis & $1 / 7 \quad(14)$ \\
\hline Peripheral T-cell lymphoma, not further specified & $1 / 14 \quad(7)$ \\
\hline Mycosis fungoides, in large cell transformation, CD30+ & $1 / 1(100)$ \\
\hline Follicular lymphoma (all grades) & $0 / 24$ \\
\hline Mantle cell lymphoma & $0 / 13$ \\
\hline Marginal zone B-cell lymphoma & $0 / 12$ \\
\hline Precursor lymphoblastic leukemia/lymphoma & $0 / 10$ \\
\hline B-cell & $0 / 7$ \\
\hline T-cell & $0 / 3$ \\
\hline Chronic lymphocytic leukemia/small lymphocytic lymphoma & $0 / 7$ \\
\hline Burkitt lymphoma & $0 / 7$ \\
\hline Mycosis fungoides, small cell type (patch or plaque) & $0 / 4$ \\
\hline Lymphoplasmacytic lymphoma/Waldenstrom macroglobulinemia & $0 / 2$ \\
\hline Plasmacytoma & $0 / 2$ \\
\hline \multicolumn{2}{|l|}{ Hodgkin's Disease } \\
\hline Nodular sclerosis & $1 / 32(3)$ \\
\hline Mixed cellularity & $0 / 8$ \\
\hline Nodular lymphocyte predominant & $0 / 3$ \\
\hline
\end{tabular}


Forty of $49(82 \%)$ cases of systemic anaplastic large cell lymphoma were positive for clusterin. The percentages of positive cells ranged from approximately $10 \%$ to over $75 \%$, with most cases having greater than $50 \%$ positive cells with strong intensity of immunostaining (Figs. 1 and 2).

In this group, we correlated clusterin with expression other molecules that had been assessed during the diagnostic workup. Mucin 1 (MUC1, also known as epithelial membrane antigen) results were available for 44 cases. Twenty-two of $37(60 \%)$ clusterinpositive neoplasms were positive for MUC1 compared with 1 of 7 (14\%) clusterin-negative neoplasms ( $P=.04$; Fisher's exact test). No other molecules assessed correlated with clusterin. In particular, 45 systemic anaplastic large cell lymphomas were assessed for anaplastic lymphoma kinase (ALK) using the ALK-1 antibody (DAKO, Carpinteria, CA) including 36 clusterin-positive cases. Seventeen (38\%) systemic anaplastic large cell lymphomas were positive for ALK: 16 of 36 (44\%) clusterinpositive neoplasms and 1 of 9 (11\%) clusterinnegative neoplasms (not statistically significant; Fisher's exact test). BCL-2 results were also available for 34 cases of systemic anaplastic large cell lymphoma. Thirteen of 28 (46\%) clusterin-positive neoplasms were positive for BCL-2 compared with 5 of $6(83 \%)$ clusterin-negative neoplasms (not statistically significant; Fisher's exact test).

We also assessed 29 cases of cutaneous anaplastic large cell lymphoma and clusterin was positive in $12(41 \%)$. The number of clusterin-positive cells ranged from $5 \%$ to $20 \%$ (Fig. 3) in most cases and staining intensity was moderate to strong. However, a small subset of cutaneous anaplastic large cell lymphomas had numerous clusterin-positive cells, greater than $50 \%$. Twenty-eight of 29 cutaneous anaplastic large cell lymphomas were negative for ALK. The one ALK+ case was also positive for clusterin. Clinical and radiological examination of

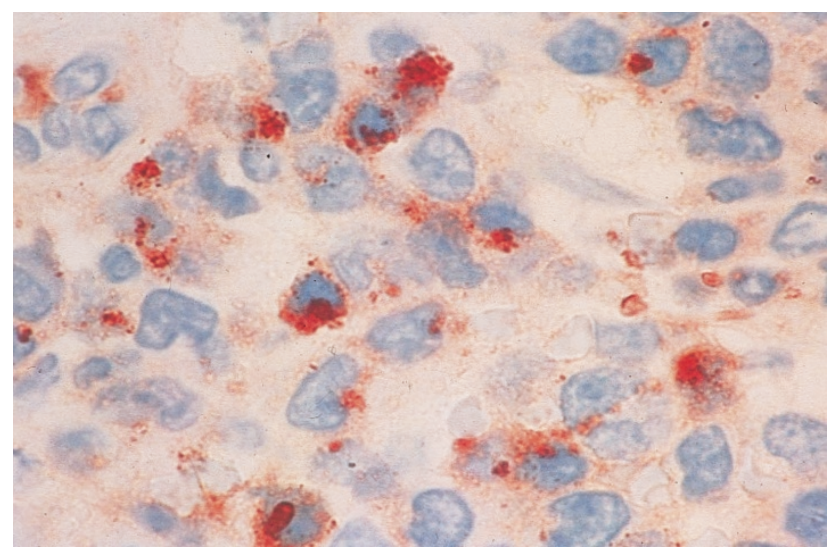

FIGURE 1. Systemic anaplastic large cell lymphoma, ALK+, with strong clusterin immunoreactivity in a paranuclear (golgi) pattern. (immunoperoxidase with hematoxylin counterstain, 400x)

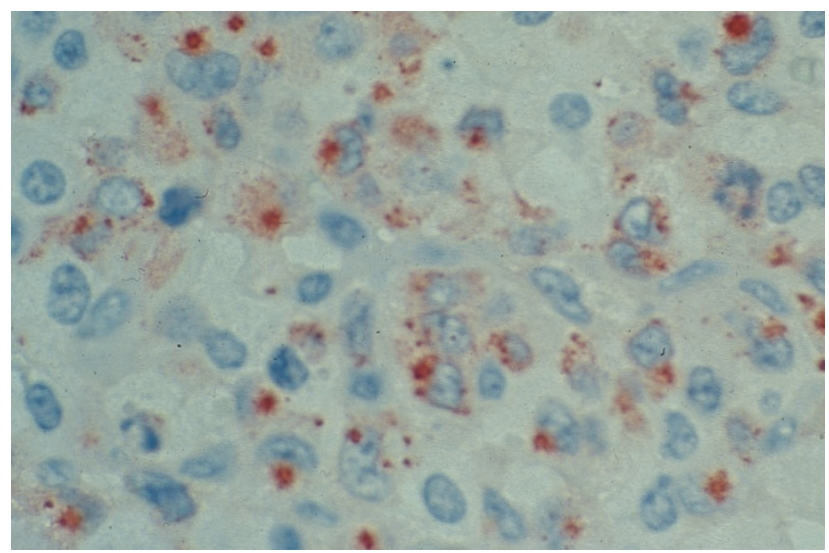

FIGURE 2. Systemic anaplastic large cell lymphoma, ALK-, with strong clusterin immunoreactivity. (immunoperoxidase with hematoxylin counterstain, 400x)

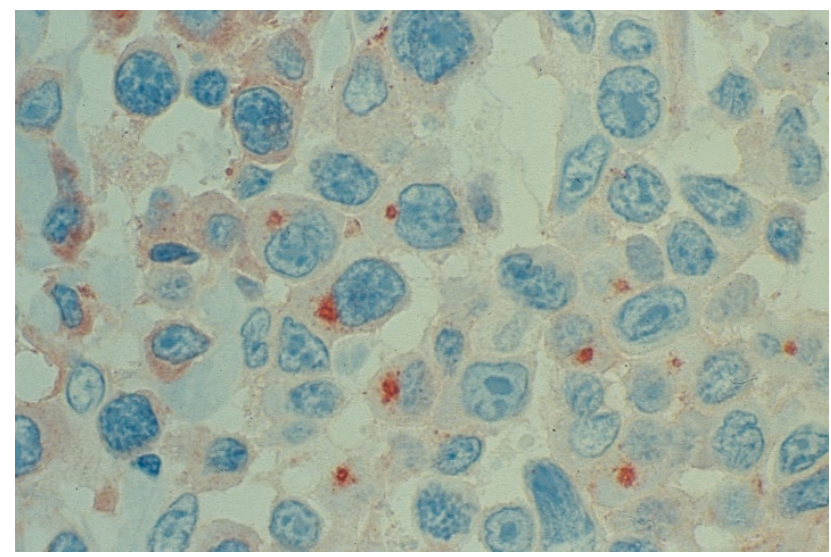

FIGURE 3. Cutaneous anaplastic large cell lymphoma, ALK-, with strong clusterin immunoreactivity but in a lesser number of cells than observed in most systemic anaplastic large cell lymphomas. (immunoperoxidase with hematoxylin counterstain, 400x)

the patient with ALK + cutaneous anaplastic large cell lymphoma revealed no other sites of disease except skin. One of seven (14\%) cases of lymphomatoid papulosis was also positive for clusterin; this case was ALK-. Very few of these cases had been assessed for MUC1 or BCL-2.

Clusterin immunostaining was uncommon in other types of lymphoid neoplasms, and when present was usually detected in a small percentage (5-10\%) of neoplastic cells. Clusterin was positive in 5 of 43 (12\%) diffuse large B-cell lymphomas. Four clusterin-positive diffuse large B-cell lymphomas had anaplastic cytologic features and four of five were diffusely positive for CD30. One clusterinpositive anaplastic diffuse large B-cell lymphoma that extensively involved lymph node sinuses was CD30-.

Other lymphoma types rarely positive for clusterin included 1 of 14 (7\%) cases of peripheral T-cell lymphoma, 1 case of mycosis fungoides in large cell transformation, and 1 of 32 (3\%) cases of nodular 
sclerosis Hodgkin's disease. The clusterin-positive case of peripheral T-cell lymphoma had a subset of cells that were positive for CD30, but this case lacked histologic features of anaplastic large cell lymphoma or any other unique histologic features and many neoplastic cells were CD30-. The clusterin-positive case of mycosis fungoides in large cell transformation arose in a patient with a long history of small cell mycosis fungoides. The tumor was diffusely CD30+ and ALK-. The single case of clusterin-positive nodular sclerosis Hodgkin's disease was grade 2 . The neoplastic cells in this case were positive for CD15 and CD30 and negative for CD3 and CD20. Long-range polymerase chain reaction analysis of frozen tissue of this case showed no evidence of the $\mathrm{t}(2 ; 5)$ (p23; $\mathrm{q} 35)$.

Clusterin also stained follicular dendritic cells, with a coarse cytoplasmic pattern. In one case of diffuse large B-cell lymphoma and one case of nodular sclerosis Hodgkin's disease, clusterin immunostaining surrounding neoplastic cells was abundant and resembled a membranous pattern. We interpreted this pattern as clusterin-positive dendritic cells surrounding neoplastic cells. In these cases no cytoplasmic expression was observed and thus we considered these two cases negative. However, we cannot completely exclude membranous staining in these two neoplasms.

Clusterin was negative in all other tumors assessed including 133 cases of non-Hodgkin's lymphoma and 42 cases of Hodgkin's disease (Table 1). Thirty-eight (88\%) diffuse large B-cell lymphomas were negative. Four of these cases had anaplastic cytologic features and 11 of 13 cases assessed for CD30 were positive: 4 diffusely (3 anaplastic) and 8 focally (1 anaplastic). Twenty-four follicular lymphomas were assessed including five grade 1, eight grade 2, and 11 grade 3; eight had diffuse areas (six were grade 3 ). The 13 negative cases of peripheral T-cell lymphoma included 11 neoplasms not further specified and 2 neoplasms with features of angioimmunoblastic T-cell lymphoma. The 13 mantle cell lymphomas assessed included neoplasms with predominantly mantle zone $(n=1)$, nodular $(n=3)$, and diffuse $(n=9)$ patterns. One mantle cell lymphoma had blastoid cytologic features. The 12 marginal zone B-cell lymphomas analyzed included seven of extranodal mucosaassociated lymphoid tissue (MALT)-type, three of nodal-type (monocytoid B-cell lymphoma), and two of splenic-type. The 10 precursor lymphoblastic leukemia/lymphoma cases studied included seven B-cell and three T-cell. The precursor B-cell lymphoblastic leukemia/lymphoma cases were derived from a clinicopathologic study published previously (20). The 42 clusterin-negative cases of Hodgkin's disease included 28 nodular sclerosis, 8 mixed cellularity, and 3 nodular lymphocyte pre- dominant. These nodular sclerosis cases were graded using the system of MacLennan and colleagues (21) as grade $1(n=8)$ and grade $2(n=20)$.

\section{DISCUSSION}

We surveyed 266 malignant lymphomas of various types for clusterin expression. In agreement with Wellmann and colleagues (16), we observed that clusterin is expressed by most cases of systemic anaplastic large cell lymphoma. In this study we also extended earlier observations by assessing clusterin expression in a large number of cases of cutaneous anaplastic large cell lymphoma and in diffuse large B-cell lymphomas with anaplastic cytologic features.

Forty of $49(82 \%)$ cases of systemic anaplastic large cell lymphoma were positive for clusterin. This frequency of clusterin immunostaining in systemic anaplastic large cell lymphoma, $82 \%$, is lower than that reported by Wellmann and colleagues (16) who detected clusterin in all 36 cases (100\%) they assessed. The explanation for this discrepancy is uncertain, but one possibility may be the heterogeneous fixation and processing of the tissues in this study, as many of the cases we assessed were processed elsewhere initially and subsequently referred to our hospital for review. Clusterin expression correlated with MUC1 positivity, but not with ALK or BCL-2. The correlation of clusterin with MUC1 has not been reported previously. Others, in abstract form, have suggested that clusterin expression in anaplastic large cell lymphoma correlates with ALK positivity (22). Although ALK+ neoplasms were also more commonly clusterin-positive in this study, $94 \%$ versus $71 \%$ for ALK - neoplasms, this difference was not statistically significant.

The results of Wellmann and colleagues (16) also suggested that clusterin expression is unique to systemic anaplastic large cell lymphoma as all nine cases of cutaneous anaplastic large cell lymphoma they assessed were negative. This is not our experience as we observed clusterin expression in 12 of $29(41 \%)$ cases of cutaneous anaplastic large cell lymphoma, although these cases had a generally lower number of positive cells than cases of systemic anaplastic large cell lymphoma. One case was ALK + . Although this patient had no clinical or radiological evidence of disease elsewhere, we cannot completely exclude the possibility that this patient had systemic anaplastic large cell lymphoma involving skin. Nevertheless, 11 of 28 (39\%) cases of ALK - cutaneous anaplastic large cell lymphoma in this study were clusterin-positive. We also detected clusterin immunostaining in 1 of 7 (14\%) cases of lymphomatoid papulosis, a disorder closely related to cutaneous anaplastic large cell lymphoma (17). 
Recently, in abstract form, Lae and colleagues (23) also reported clusterin expression in 5 of 9 (56\%) cases of primary cutaneous anaplastic large cell lymphoma.

Clusterin was also expressed in 5 of $43(12 \%)$ diffuse large B-cell lymphomas. Four $(80 \%)$ of these cases had anaplastic cytologic features. In contrast, anaplastic cytologic features were present in 4 of 38 (11\%) clusterin-negative diffuse large B-cell lymphoma ( $P=.005$; Fisher's exact test). These findings raise the possibility that clusterin expression is associated with anaplastic cytologic features irrespective of lineage or disease-specific mechanisms. However, clusterin expression in diffuse large B-cell lymphomas was generally less intense and in fewer cells than was observed in systemic anaplastic large cell lymphoma.

Anaplastic large cell lymphoma, as defined in the World Health Organization (24), exhibits a wide spectrum of histologic findings that can be subdivided into morphologic variants that histologically overlap with classical Hodgkin's disease and other types of non-Hodgkin's lymphoma (25-27). For these cases, immunohistochemical studies are extremely valuable in distinguishing anaplastic large cell lymphoma from its morphologic mimics. Although many antibodies have been used to distinguish anaplastic large cell lymphoma from Hodgkin's disease, the most important include those specific for T- and B-cell antigens, CD15, CD30, CD45RB (LCA), and MUC1 (EMA) (24, 25, 28). The classical immunophenotype of T-cell anaplastic large cell lymphoma is CD15-, CD30+, $\mathrm{CD} 45 \mathrm{RB}+, \mathrm{ALK}+, \mathrm{MUC1}+$, T-cell antigens positive, and B-cell antigens negative. This immunophenotype contrasts with that of classical Hodgkin's disease in which the Reed-Sternberg and Hodgkin cells are $\mathrm{CD} 15+, \mathrm{CD} 30+, \mathrm{CD} 45 \mathrm{RB}-, \mathrm{ALK}-$, MUC1-, T-cell antigens negative, and B-cell antigens variably positive. Thus, in typical cases the results of immunohistochemical studies can distinguish anaplastic large cell lymphoma from Hodgkin's disease. However, anaplastic large cell lymphomas commonly vary from their typical immunophenotype. For example, leukocyte common antigen (CD45RB) is negative in up to $30-40 \%$ of cases of anaplastic large cell lymphoma (25). PanT-cell antigens, such as CD3 and CD5, are also commonly negative in T-cell anaplastic large cell lymphoma and, by definition, are absent in nullcell anaplastic large cell lymphoma. ALK is positive in only a subset of anaplastic large cell lymphomas $(21,24)$. Thus, cases of anaplastic large cell lymphoma exist in which immunohistochemical results are similar to classical Hodgkin's disease, and an additional immunohistochemical marker would be of value in the differential diagnosis of these neoplasms. The results of this study support those reported previously by Wellmann and colleagues (16) and suggest that clusterin may be a valuable addition to antibody panels designed to distinguish anaplastic large cell lymphoma from Hodgkin's disease.

In summary, in this study clusterin was positive in approximately $80 \%$ of systemic anaplastic large cell lymphomas. However, clusterin was also expressed in approximately $40 \%$ of cutaneous anaplastic large cell lymphomas, $10 \%$ of diffuse large B-cell lymphomas and was observed in rare cases of peripheral T-cell lymphoma and nodular sclerosis Hodgkin's disease.

\section{REFERENCES}

1. Blaschuk O, Burdzy K, Fritz IB. Purification and characterization of a cell-aggregating factor (clusterin), the major glycoprotein in ram rete testis fluid. J Biol Chem 1983;258: 7714-20.

2. Griswold MD, Roberts K, Bishop P. Purification and characterization of a sulfated glycoprotein secreted by Sertoli cells. Biochemistry 1986;25:7265-70.

3. Kirszbaum L, Bozas SE, Walker ID. SP-40, 40, a protein involved in the control of the complement pathway, possesses a unique array of disulfide bridges. FEBS Lett 1992; 297:70-6.

4. Rosenberg ME, Silkensen J. Clusterin: physiologic and pathophysiologic considerations. Int J Biochem Cell Biol 1995;27:633-45.

5. Fink TM, Zimmer M, Tschopp J, Etienne J, Jenne DE, Lichter P. Human clusterin (CL1) maps to $8 \mathrm{p} 21$ in proximity to the lipoprotein lipase (LPL) gene. Genomics 1993;16:526-8.

6. Purrello M, Bettuzzi S, Di Pietro C, Mirabile E, Di Blasi M, Rimini R, et al. The gene for SP-40, 40, human homologue of rat sulfated glycoprotein 2, rat clusterin, and rat testosterone-repressed prostate message 2, maps to chromosome 8. Genomics 1991;10:151-6.

7. Hochgrebe TT, Humphreys D, Wilson R, Easterbrook-Smith SB. A reexamination of the role of clusterin as a complement regulator. Exp Cell Res 1999;249:13-21.

8. Humphreys DT, Carver JA, Easterbrook-Smith SB, Wilson MR. Clusterin has chaperone-like activity similar to that of small heat shock proteins. J Biol Chem 1999;274:6875-81.

9. Zwain I, Amato P. Clusterin protects granulosa cells from apoptotic cell death during follicular atresia. Exp Cell Res 2000;257:101-10.

10. Yang CR, Leskov K, Hosley-Eberlein K, Criswell T, Pink JJ, Kinsella TJ, et al. Nuclear clusterin/XIP8, an X-ray-induced Ku70-binding protein that signals cell death. Proc Natl Acad Sci USA 2000;97:5907-12.

11. Redondo M, Villar E, Torres-Munoz J, Tellez T, Morell M, Petito CK. Overexpression of clusterin in human breast carcinoma. Am J Pathol 2000;157:393-9.

12. Miyake H, Gleave M, Kamidono S, Hara I. Overexpression of clusterin in transitional cell carcinomea of the bladder is related to disease progression and recurrence. Urology 2002; 59:150-4.

13. Miyake H, Hara S, Arakawa S, Kamidono S, Hara I. Over expression of clusterin is an independent prognostic factor for nonpapillary renal cell carcinoma. J Urol 2002;167:703-6.

14. Steinberg J, Oyasu R, Lang S, Sintich S, Rademaker A, Lee C, et al. Intracellular levels of SGP-2 (clusterin) correlate with tumor grade in prostate cancer. Clin Cancer Res 1997;3: $1707-11$ 
15. Hough CD, Cho KR, Zonderman AB, Schwartz DR, Morin PJ. Coordinately up-regulated genes in ovarian cancer. Cancer Res 2001;61:3869-76.

16. Wellmann A, Thieblemont C, Pittaluga S, Sakai A, Jaffe ES, Siebert $\mathrm{P}$, et al. Detection of differentially expressed genes in lymphomas using cDNA arrays: identification of clusterin as a new diagnostic marker for anaplastic large-cell lymphomas. Blood 2000;96:398-404.

17. Ralfkiaer E, Delsol G, Willemze R, Jaffe ES. Primary cutaneous CD30-positive T-cell lymphoproliferative disorders. In: Jaffe ES, Harris NL, Stein H, Vardiman JW, editors. Tumours of haematopoietic and lymphoid tissues. Pathology and genetics. World Health Organization Classification of Tumours. Lyon, France: IARC Press; 2001. pp. 221-4.

18. Rassidakis GZ, Sarris AH, Herling M, Ford RJ, Cabanillas F, McDonnell TJ, et al. Differential expression of BCL-2 family proteins in ALK-positive and ALK-negative anaplastic large cell lymphoma of T/null-cell lineage. Am J Pathol 2001;159: 527-35.

19. Park C-K, Manning JT, Battifora H, Medeiros LJ. Follicle center lymphoma and Warthin tumor involving the same anatomic site: report of two cases and review of the literature. Am J Clin Pathol 2000;113:113-9.

20. Lin P, Jones D, Dorfman DM, Medeiros LJ. Precursor B-cell lymphoblastic lymphoma: a predominantly extranodal tumor with low propensity for leukemic involvement. Am J Surg Pathol 2000;24:1480-90.

21. MacLennan KA, Bennett MH, Tu A, Hudson BV, Easerling MJ, Hudson GV, et al. Relationship of histopathologic features to survival and relapse in nodular sclerosing Hodgkin's disease. A study of 1659 patients. Cancer 1989;64:1686-93.
22. Aoun P, Greiner TC, Lynch JC, Vose JM, Gordon BG, Chan WC, et al. Clusterin expression is associated with anaplastic large cell lymphoma (ALCL) of T/null cell phenotype with ALK expression [abstract \#830]. Mod Pathol 2000;13:142A.

23. Lae ME, Ahmed I, Macon WR. Clusterin is widely expressed in systemic anaplastic large cell lymphoma (ALCL) but fails to differentiate primary from secondary cutaneous ALCL [abstract \#1037]. Mod Pathol 2002;15:249A.

24. Delsol G, Ralfkiaer E, Stein H, Wright D, Jaffe ES. Anaplastic large cell lymphoma. In: Jaffe ES, Harris NL, Stein H, Vardiman JW, editors. Tumours of haematopoietic and lymphoid tissues. Pathology and genetics. World Health Organization Classification of Tumours. Lyon, France: IARC Press; 2001. pp. 230-5.

25. Benharroch D, Meguerian-Bedoyan Z, Lamant L, Amin C, Brugieres L, Terrier-Lacombe MJ, et al. ALK-positive lymphoma: a single disease with a broad spectrum of morphology. Blood 1998;91:2076-84.

26. Haralambieva E, Pulford KA, Lamant L, Pileri S, Roncador G, Gatter KC, et al. Anaplastic large-cell lymphomas of B-cell phenotype are anaplastic lymphoma kinase (ALK) negative and belong to the spectrum of diffuse large B-cell lymphomas. Br J Hematol 2000;109:584-91.

27. Lai R, Medeiros LJ, Dabbagh L, Formenti KS, Coupland RW. Sinusoidal CD30-positive large B-cell lymphoma: a morphologic mimic of anaplastic large cell lymphoma. Mod Pathol 2000;13:223-8.

28. Chittal SM, Caveriviere P, Schwarting R, Gerdes J, Al Saati T, Rigal-Huet F, et al. Monoclonal antibodies in the diagnosis of Hodgkin's disease. The search for a rational panel. Am J Surg Pathol 1988;12:9-21. 